\title{
Pengaruh Kecepatan Rotasi Pahat dan Kecepatan Pengelasan terhadap Sifat Mekanis Hasil Pengelasan Friction Stir Logam Tak Sejenis Aluminium 5052 H3 dan Tembaga
}

\author{
Sulardjaka*, Deni Fajar Fitriyana, Ayus Dios Bawono \\ Departemen Teknik Mesin, Fakultas Teknik, Universitas Diponegoro \\ Jl. Prof. Sudharto, SH., Tembalang-Semarang 50275, Telp. +62247460059 \\ *e-mail: sulardjaka@undip.ac.id
}

\begin{abstract}
The effect of rotational tool shoulder and welding speed, on mechanical properties of friction stir welding (FSW) of AA $5052 \mathrm{H3}$ and pure copper have been investigated. The CNC milling machine was used for FSW processes. Tool shoulder of FSW processes made from quenched hardened H13 steel with cone pin. The FSW were done on variation tool rotations: $2850 \mathrm{rpm}, 3000 \mathrm{rpm}$ and $3150 \mathrm{rpm}$. Welding speed of FSW were $100 \mathrm{~mm} / \mathrm{min}$ and $120 \mathrm{~mm} / \mathrm{min}$. The result shows that welding at parameter $3000 \mathrm{rpm}$ tool rotation and $100 \mathrm{~mm} / \mathrm{minute}$ has highest tensile strength $(223 \mathrm{MPa})$.
\end{abstract}

Keywords: friction stir welding, aluminium, copper, dissimilar

\begin{abstract}
Abstrak
Tujuan penelitian ini meneliti pengaruh variasi kecepatan rotasi pahat dan kecepatan pengelasan, terhadap sifat mekanis pengelasan FSW AA 5052 H3 dengan tembaga. Pengelasan FSW dilakukan dengan menggunakan mesin milling CNC. Tool shoulder dibuat dengan baja H13 yang dikeraskan dengan metode quench hardening dengan pin berbentuk kerucut. Pengelasan FSW dilakukan dengan variasi rotasi pahat: $2850 \mathrm{rpm}, 3000 \mathrm{rpm}$, dan $3150 \mathrm{rpm}$, Kecepatan pengelasan FSW: $100 \mathrm{~mm} / \mathrm{min}$ dan $120 \mathrm{~mm} / \mathrm{min}$. Hasil penelitian menunjukkan bahwa kekuatan tarik tertinggi dihasilkan pada pengelasan dengan kecepatan putaran $3000 \mathrm{rpm}$ dan dengan kecepatan pengelasan $100 \mathrm{~mm} / \mathrm{menit}$ yaitu sebesar $223 \mathrm{MPa}$.
\end{abstract}

Kata kunci: friction stir welding, aluminium, tembaga, logam tak sejenis

\section{Pendahuluan}

Friction stir welding (FSW) adalah proses penggabungan material yang termasuk dalam kelompok pengelasan fasa padat (solid state). Proses ini memanfaatkan deformasi pada suhu tinggi. FSW menghasilkan sambungan dengan hasil pengelasan yang menguntungkan. Pada FSW, daerah logam las dan daerah terkena pengaruh panas (heat affected zone/HAZ) tidak terpengaruh seperti pada pengelasan listrik konvensional [1]. Material logam yang dilas dengan metode FSW, mendapatkan panas dari gesekan shoulder. Efek panas ini yang mengakibatkan pergerakan dari butirbutir pada kedua bagian yang dilas, berpindah dan mengalami pengadukan. Daerah yang dipengaruhi panas tersebut dapat dibagi menjadi beberapa daerah. Daerah hasil pengelasan FSW diklasifikasikan menjadi 4 bagian yaitu: welding nugget, thermomechanincally affected zone, heat affected zone dan base metal [2]. FSW banyak diteliti untuk digunakan pada pengelasan paduan aluminium, paduan tembaga, paduan magnesium, paduan titanium, baja tahan karat dan komposit matriks logam (MMC) [3].

Pengelasan fasa padat FSW memungkinkan untuk digunakan pada pengelasan material logam yang tidak sejenis. Metode FSW telah berhasil digunakan untuk mengelas material aluminum dan magnesium. Penelitian tersebut menunjukkan bahwa FSW dapat digunakan untuk menyambung material dengan perbedaan titik leleh cukup tinggi [4]. Penyambungan dengan metode FSW untuk menyambung material tidak sejenis antara logam aluminium dan tembaga juga telah mulai diteliti. FSW telah berhasil digunakan untuk menyambung material aluminium dengan tembaga yang di-anil dan menghasilkan kekuatan tarik hingga $148 \mathrm{Mpa}$ [5-7]. Pengelasan logam tak sejenis aluminium dan tembaga masih memiliki banyak masalah yang harus dipecahkan yaitu masih ditemuinya retak, lubang atau cacat pada sambungan sehingga sifat mekanis sambungan masih rendah [8, 9]. Permasalahan pada pengelasan logam tak sejenis aluminium dan tembaga adalah adanya void pada daerah sambungan, tunnel defect, ketidaksempurnaan penetrasi (percampuran) antara logam aluminium dan tembaga serta terbentuknya campuran antar logam (intermetallic compounds/IMCs) yang bersifat keras dan getas pada stir zone. Terbentuknya IMCs mengakibatkan timbulnya retak dan menurunnya kekuatan sambungan [9 -13].

Pada penelitian ini, diteliti pengaruh kecepatan putaran tool shoulder dan kecepatan pengelasan terhadap kekuatan tarik dan distribusi kekerasan pada hasil pengelasan FSW antara logam paduan aluminium $5052 \mathrm{H} 3$ dengan tembaga. 


\section{Material dan metode penelitian}

Bahan yang diteliti adalah plat aluminium paduan $5052 \mathrm{H} 3$ dan plat tembaga murni dengan ukuran $200 \mathrm{x} 100 \mathrm{~mm}$ dengan ketebalan $3 \mathrm{~mm}$. Material untuk bahan tool shoulder adalah baja H13 (hot work steel). Tool shoulder dikeraskan dengan perlakuan quench hardening kemudian ditemper. Diameter shoulder $20 \mathrm{~mm}$, sedangkan pin berbentuk kerucut dengan diameter dasar 4,5 $\mathrm{mm}$ dan diameter ujung 0,2 $\mathrm{mm}$. Gambar dimensi tool shoulder untuk pengelasan FSW ditunjukkan pada Gambar 1. Proses pengelasan FSW dilakukan dengan mesin milling CNC. Pengelasan dilakukan dengan variasi kecepatan rotasi pahat: $2850 \mathrm{rpm}, 3000 \mathrm{rpm}$, dan $3150 \mathrm{rpm}$. Parameter kecepatan pengelasan: 100 $\mathrm{mm} / \mathrm{min}$ dan $120 \mathrm{~mm} / \mathrm{min}$.

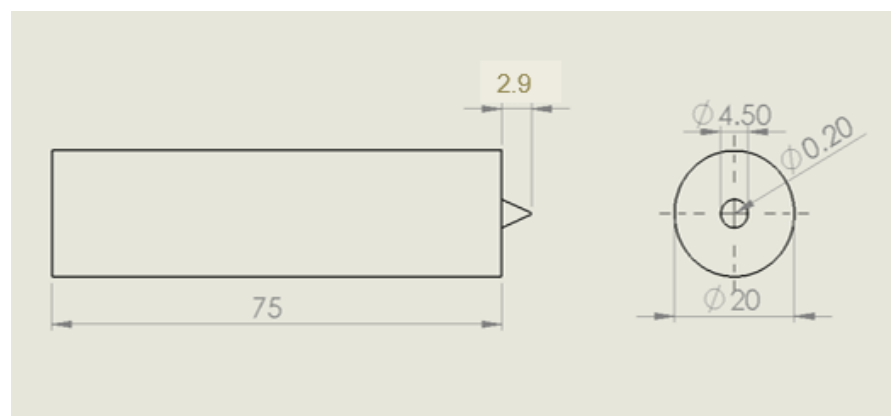

Gambar 1. Dimensi Tool Shoulder untuk FSW

Pengujian mekanis yang dilakukan adalah pengujian kekerasan mikro, pengujian tarik. Pengujian kekerasan mikro dilakukan dengan menggunakan mesin uji kekerasan mikro Vickers. Uji kekerasan dilakukan dengan mengacu pada standarisasi ASTM E 384 - 99. Pengujian kekerasan mikro dilakukan dari bagian tengah sambungan (titik nol) ke bagian logam aluminium dan tembaga dengan interval tiap $0,5 \mathrm{~mm}$. Pengambilan data kekerasan dari bagian tengah welding nugget $5 \mathrm{~mm}$ menuju arah aluminium dan arah tembaga. Pengujian dilakukan pada daerah weld nugget, TMAZ, $H A Z$, dan base metal. Secara skematik pengambilan titik pengujian kekerasan ditunjukkan pada Gambar 2. Pengujian tarik dilakukan dengan mesin uji tarik universal testing machine, berdasarkan standarisasi ASTM E 8 - 99. Foto spesimen uji tarik ditunjukkan pada Gambar 3.

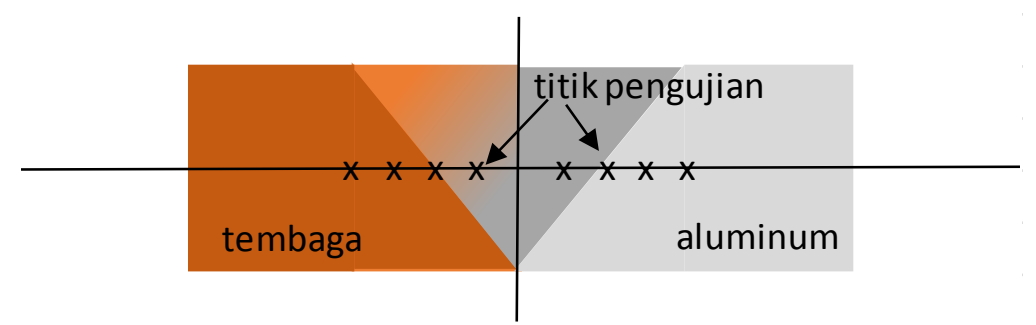

Gambar 2. Pengujian Kekerasan Mikro Hasil Pengelasan FSW

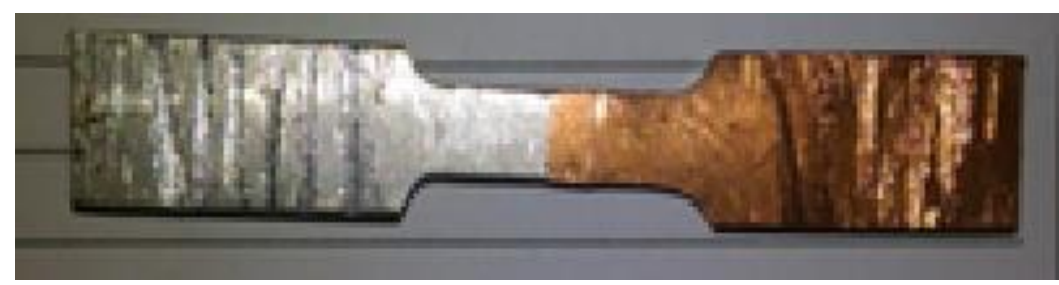

Gambar 3. Foto Spesimen Uji Tarik

\section{Hasil dan Pembahasan}

Hasil uji tarik pada sambungan pengelasan FSW ditunjukkan pada Gambar 4. Nilai kekuatan tarik sambungan FSW yang tertinggi sebesar $223 \mathrm{MPa}$. Nilai kekuatan tarik ini mencapai $75-80 \%$ dari kekuatan material dasarnya. Kekuatan tarik sambungan tertinggi didapat dari pengelasan FSW dengan parameter kecepatan rotasi pahat 3000 dan kecepatan pengelasan $100 \mathrm{~mm} / \mathrm{min}$. Pada parameter pengelasan ini juga didapat nilai elongasi tertinggi, yaitu sebesar 6,4\%. Pengelasan FSW dengan parameter pengelasan yang lain tidak memberikan hasil kekuatan pengelasan yang baik. Hal ini bisa disebabkan hasil pengelasan tidak tebentuk welding nugget pada daerah sambungan dari kedua material (Gambar 7 dan 8). 


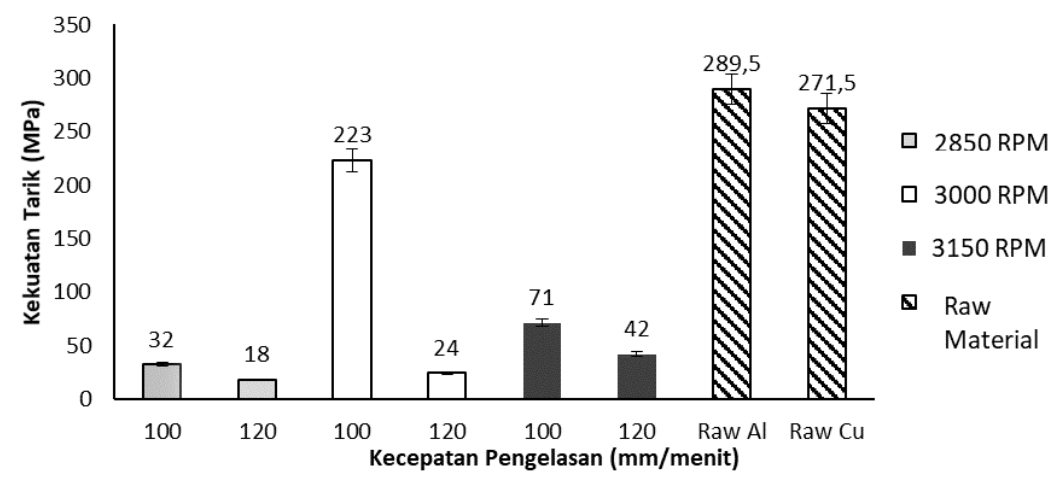

Gambar 4. Grafik Kekuatan Uji Tarik Hasil Pengelasan dan Raw Material

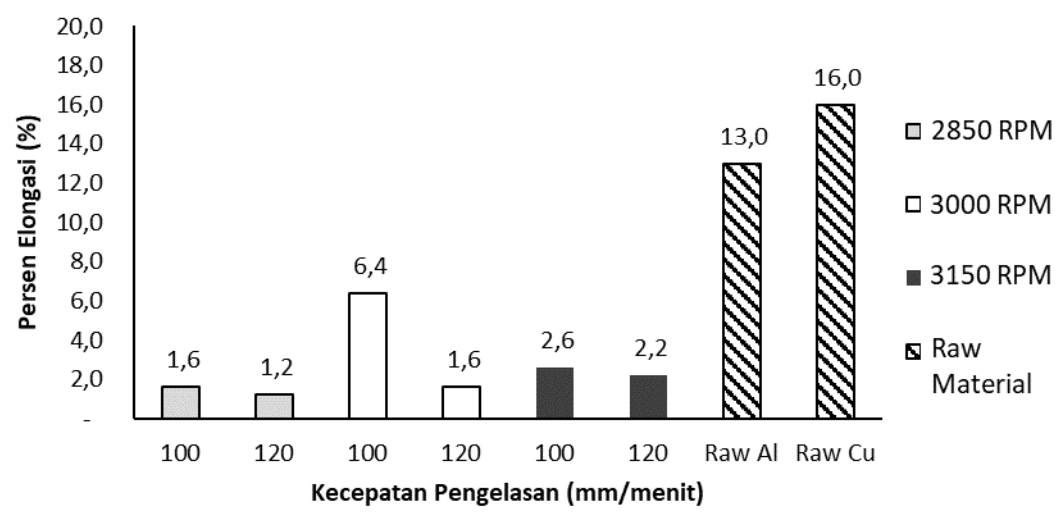

Gambar 5. Grafik \% Elongasi Hasil Pengelasan dan Raw Material

Gambar 4 dan 5 menunjukkan bahwa dari hasil pengujian tarik hasil pengelasan FSW. Dari grafik pada gambar tersebut dapat disimpulkan bahwa, pada putaran pahat yang sama, nilai kekuatan tarik pada kecepatan $100 \mathrm{~mm} / \mathrm{menit}$ lebih tinggi jika dibandingkan dengan pengelasan pada kecepatan $120 \mathrm{~mm} / \mathrm{menit}$. Pengelasan pada kecepatan 100 $\mathrm{mm} /$ menit juga memberikan \% elongasi yang lebih tinggi jika dibadingkan dengan pengelasan pada kecepatan 120 $\mathrm{mm} / \mathrm{menit}$. Hasil ini disebabkan pada kecepatan pengelasan yang rendah pergerakan butir material lebih baik dibandingkan pada kecepatan pengelasan yang lebih tinggi $[8,12,14]$. Pengelasan dengan kecepatan yang rendah, juga mengakibatkan pembangkitan panas yang lebih tinggi pada material yang dilas $[6,15]$.

Gambar 6 menunjukkan distribusi dari kekerasan hasil pengelasan FSW. Pada area weld nugget didapat nilai kekerasan rata-rata $107 \mathrm{HV}$ untuk variasi kecepatan pengelasan $120 \mathrm{~mm} / \mathrm{min}$, dan 104,5 HV untuk variasi kecepatan pengelasan $100 \mathrm{~mm} / \mathrm{min}$. Nilai rata-rata kekerasan pada TMAZ yang didapat pada daerah tembaga dan aluminium berturut-urut adalah 114,3 HV dan 87,2 HV pada variasi kecepatan pengelasan $120 \mathrm{~mm} / \mathrm{min}$, sedangkan pada variasi kecepatan pengelasan $100 \mathrm{~mm} / \mathrm{min}$ nilai rata-ratanya adalah 108,86 $\mathrm{HV}$ dan 88,36 $\mathrm{HV}$ pada bagian tembaga dan aluminium berturut-urut. Pada bagian base metal, aluminium memiliki kekerasan sebesar $78 \mathrm{HV}$ dan tembaga $115 \mathrm{HV}$. Pada pengelasan dengan parameter kecepatan rotasi $3000 \mathrm{rpm}$, dengan pengambilan data dari weld nugget pada bagian titik nol dan $5 \mathrm{~mm}$ menuju arah aluminium dan arah tembaga. Pengujian dilakukan pada area weld nugget, TMAZ, HAZ, dan base metal. Pada area weld nugget memiliki nilai kekerasan rata-rata 108,6 HV untuk variasi kecepatan pengelasan $120 \mathrm{~mm} / \mathrm{min}$, dan 107,6 HV untuk variasi kecepatan pengelasan $100 \mathrm{~mm} / \mathrm{min}$. Nilai rata-rata kekerasan pada TMAZ yang didapat pada daerah tembaga dan aluminium berturut-urut adalah $115,1 \mathrm{HV}$ dan $99,4 \mathrm{HV}$ pada variasi kecepatan pengelasan $120 \mathrm{~mm} / \mathrm{min}$, sedangkan pada variasi kecepatan pengelasan $100 \mathrm{~mm} / \mathrm{min}$ nilai rata-ratanya adalah $111 \mathrm{HV}$ dan 91,03 HV pada bagian tembaga dan aluminium berturut-urut. Hasil pengelasan dengan kecepatan rotasi $2850 \mathrm{rpm}$. Pada area welding nugget didapat nilai kekerasan 121,3 HV untuk variasi kecepatan pengelasan 120 $\mathrm{mm} / \mathrm{min}$, dan 129,2 HV untuk variasi kecepatan pengelasan $100 \mathrm{~mm} / \mathrm{min}$. Nilai rata-rata kekerasan pada TMAZ yang didapat pada daerah tembaga dan aluminium berturut-urut adalah 116,1 HV dan 98,7 HV pada variasi kecepatan pengelasan $120 \mathrm{~mm} / \mathrm{min}$, sedangkan pada variasi kecepatan pengelasan $100 \mathrm{~mm} / \mathrm{min}$ nilai rata-ratanya adalah $116,1 \mathrm{HV}$ dan 88,5 HV pada bagian tembaga dan aluminium berturut-urut.

Terjadi peningkatan nilai kekerasan pada bagian weld nugget dikarenakan terjadi percampuran antara kedua belah pihak dan pembentukan butir. Semakin rendah kecepatan rotasi maka semakin tinggi nilai kekerasan yang akan didapat, akibat deformasi plastis material yang lebih tinggi [16]. Peningkatan kekerasan yang tinggi pada daerah weld nugget 
diakibatkan oleh terbetuknya campuran antar logam (intermetallic compounds/IMCs) yang bersifat keras dan getas $[11,12]$.

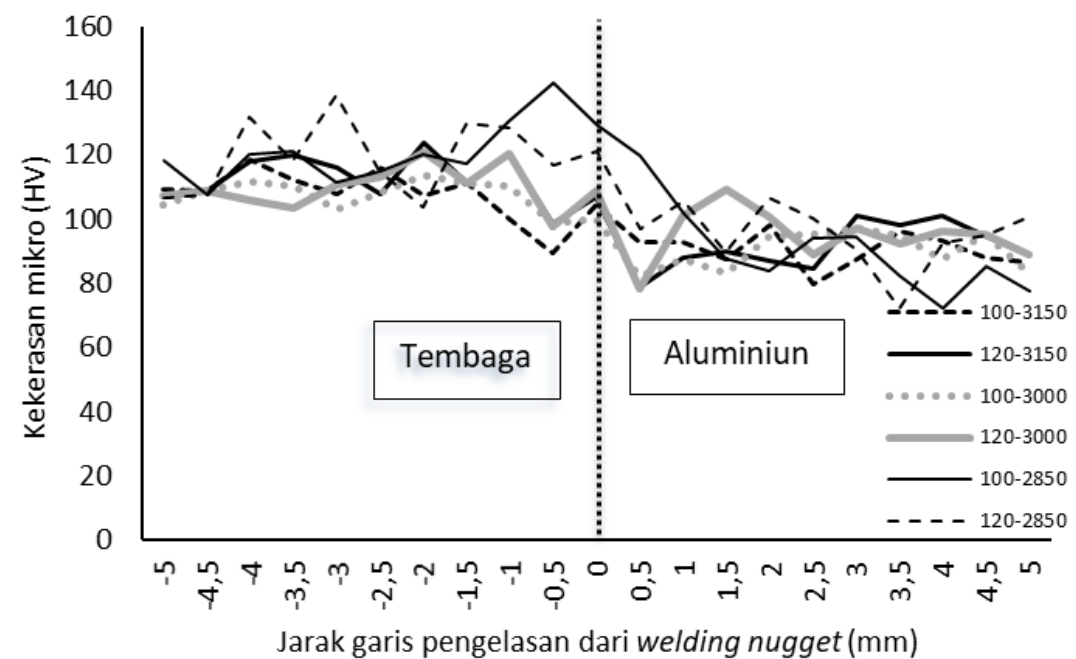

Gambar 6. Grafik Distribusi Kekerasan Hasil Pengelasan FSW

Pada Gambar 7 dan 8 menunjukkan foto makrografi FSW dengan putaran 2850 dan 3150 rpm dan kecepatan 100 $\mathrm{mm} / \mathrm{menit}$ dan $120 \mathrm{~mm} /$ menit. Pada pengelasan dengan kecepatan rotasi pahat 2850 dan 3150 didapat hasil pengelasan yang kurang sempurna. Logam aluminium dan tembaga tidak tercampur. Hasil ini dikarenakan kecepatan pengelasan yang tinggi, menagkibatkan kurangnya heat generation sehingga material tidak tersambung sempurna [10].

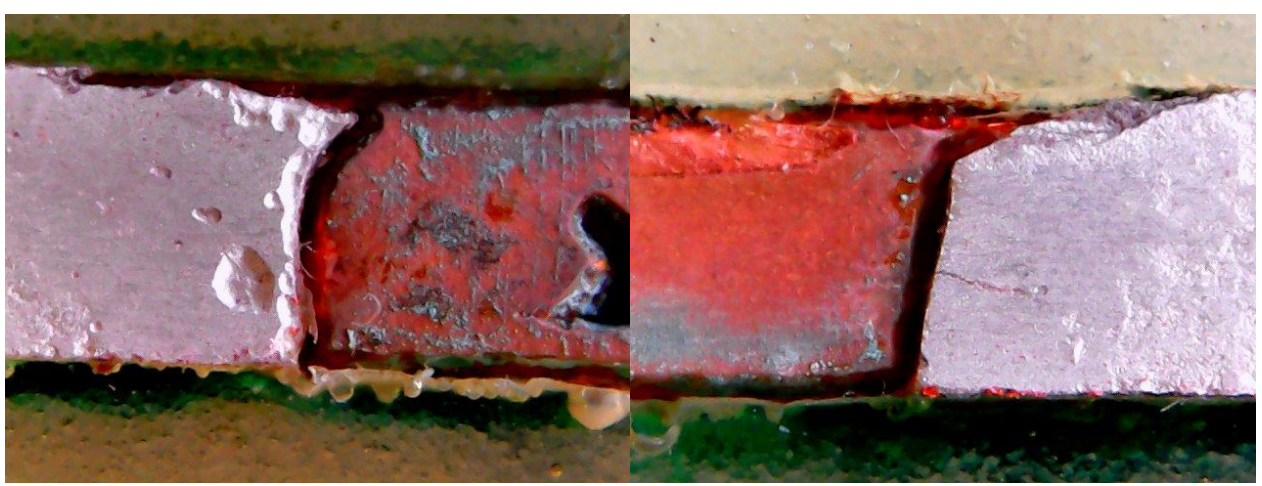

(a)

Gambar 7. Foto makro dengan variasi kecepatan putar $2850 \mathrm{rpm}$

(a) kecepatan pengelasan $100 \mathrm{~mm} / \mathrm{min}$ dan (b) kecepatan pengelasan $120 \mathrm{~mm} / \mathrm{min}$

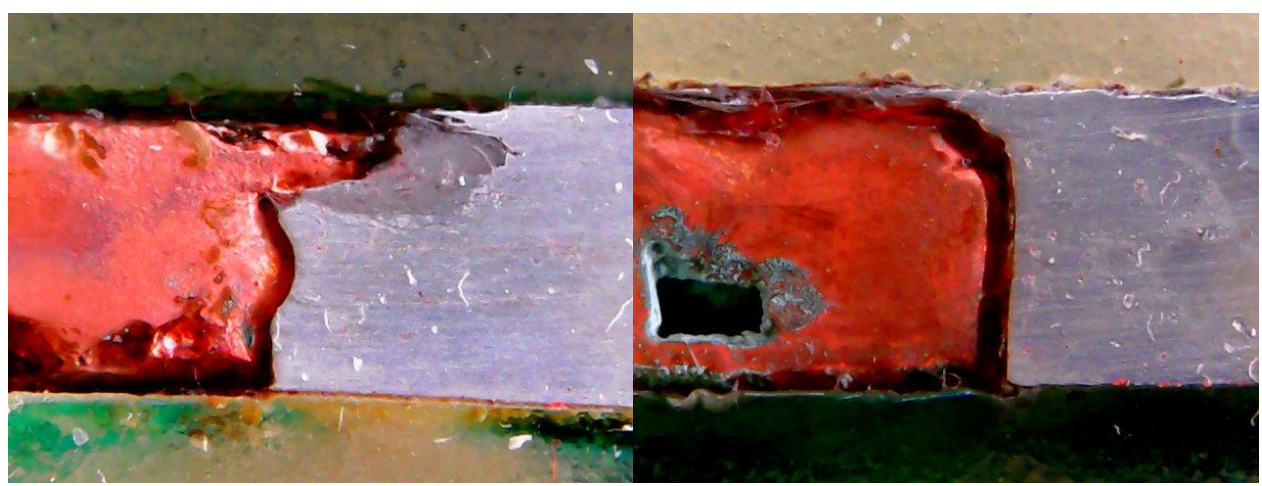

(a)

(b)

Gambar 8. Foto makro dengan variasi kecepatan putar $3150 \mathrm{rpm}$

(a) kecepatan pengelasan $100 \mathrm{~mm} / \mathrm{min}$ dan (b) kecepatan pengelasan $120 \mathrm{~mm} / \mathrm{min}$ 


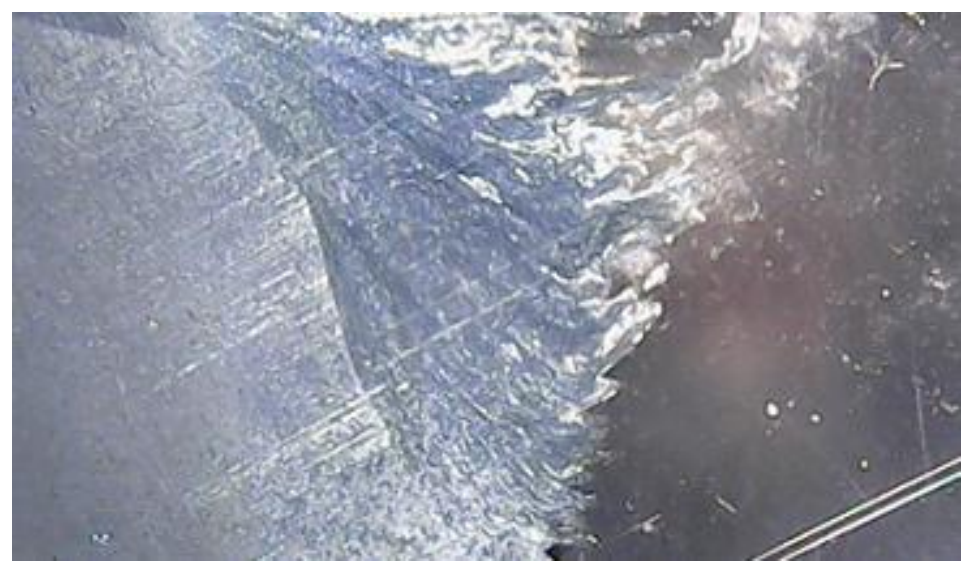

Gambar 9. Foto Makro Hasil Pengelasan FSW pada Kecepatan 100 mm/menit dan Rotasi $3000 \mathrm{rpm}$

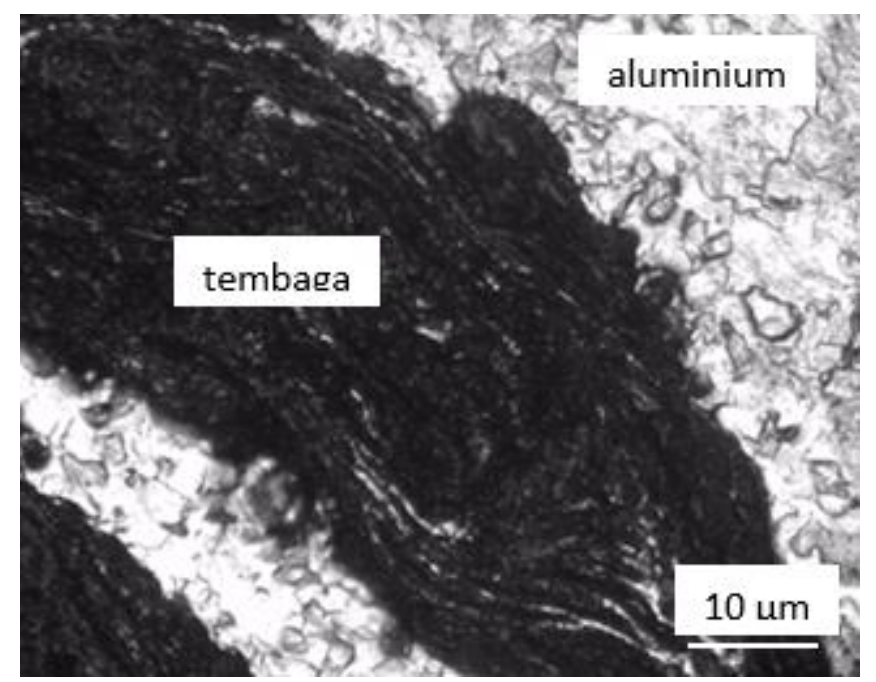

Gambar 10. Foto Makro Hasil Pengelasan FSW pada Kecepatan 100 mm/menit dan Rotasi $3000 \mathrm{rpm}$

Gambar 9 menunjukkan foto makro hasil pengelasan dengan parameter kecepatan $100 \mathrm{~mm} / \mathrm{menit}$ dan rotasi 3000 rpm. Dibanding dengan foto makro pada Gambar 7 dan 8 pengelasan pada parameter ini memberikan hasil kualitas sambungan yang lebih baik. Hal ini juga didukung dengan hasil dari uji tarik yang memberikan nilai kekuatan lebih tinggi. Foto struktur mikro dari hasil pengelasan seperti ditunjukkan pada Gambar 10 menunjukkan bahwa terjadi perpindahan atau aliran material logam aluminium dan tembaga sehingga menghasilkan kekuatan yang sambungan yang cukup baik.

\section{Kesimpulan}

Hasil pengelasan dengan parameter kecepatan rotasi pahat $2850 \mathrm{rpm}$ dan $3150 \mathrm{rpm}$ dan kecepatan pengelasan 100 $\mathrm{mm} / \mathrm{min}$ dan $120 \mathrm{~mm} / \mathrm{min}$, menggunakan geometri tool berbentuk tapered atau kerucut, dengan menggunakan offset pengelasan pada sisi tembaga ini tidak terbentuk welding nugget pada area penggabungan kedua material. Hal ini diketahui dari pengujian makrografi yang menunjukkan hasil pengelasan tidak memiliki area pengadukan, dan rata-rata memiliki celah di bagian welding nugget atau stir zone. Nilai kekuatan sambungan tertinggi didapat pada pengelasan FSW dengan kecepatan pengelasan $100 \mathrm{~mm} /$ menit dan kecepatan putaran $3000 \mathrm{rpm}$. Pengelasan pada parameter ini menghasilkan kekuatan tarik sebesar $223 \mathrm{Mpa}$ atau mencapai 75 - $80 \%$ dari kekuatan material dasarnya.

\section{Ucapan Terima Kasih}

Penulis mengucapkan terima kasih kepada Direktorat Riset dan Pengabdian Masyarakat Direktorat Jenderal Penguatan Riset dan Pengembangan Kementerian Riset, Teknologi dan Pendidikan Tinggi yang telah memberikan dana penelitian ini melalui skema penelitian PDUPT. Berdasarkan Surat Tugas No: 101-32/UN7.P4.3/PP/2018 tanggal: 5 Februari 2018.

\section{Daftar Pustaka}

[1] Sanderson, S., dan Nelson, T.W., 2011, "Effect of Processing Parameter on Friction Stir Welded HSLA-65 Charpy V Notch Impact Toughness," Proceedings of the TMS 2011 Annual Meeting \& Exhibition. California, USA. 
[2] Shinde, G., Gajghate, S., Dabeer, P.S., Seemikeri, C.Y., 2016, "Low Cost Friction Stir Welding: A Review," Materials Today: Proceedings 4: 8901-8910.

[3] Yamamura, K., Torikai, K., Nishimura, T., 2011, "Mechanical Interlock of Thin Metallic Using Friction Stir Forming," Proceedings of the TMS 2011 Annual Meeting \& Exhibition. California, USA.

[4] Mohammadi,J., Behnamian, Y., Mostafaei, A., Izadi, H., Saeid, T., Kokabi, A.H., Gerlich, A.P., 2015, "Friction stir welding joint of dissimilar materials between AZ31B magnesium and 6061 aluminum alloys: Microstructure studies and mechanical characterizations," Materials Characterization 101: 189-207

[5] Carlone, P., Astarita,A., Palazzo, G.S., Paradiso,V., Squillace,A., 2015," Microstructural aspects in Al-Cu dissimilar joining by FSW," The International Journal of Advanced Manufacturing Technology, 79(5-8):11091116.

[6] Wei Zhang, Yifu Shen, Yinfei Yan, Rui Guo, 2017, "Dissimilar friction stir welding of $6061 \mathrm{Al}$ to T2 pure Cu adopting toothshaped joint configuration: Microstructure and mechanical properties," Materials Science \& Engineering A 690: 355-364.

[7] Jingqing Zhang, Yifu Shen, Xin Yao, Haisheng Xu, Bo Li, 2014, "Investigation on dissimilar underwater friction stir lap welding of 6061-T6 aluminum alloy to pure copper," Materials and Design 64: 74-80.

[8] Sulardjaka dan Umam, R.S., 2017, "Pengaruh Kecepatan Putaran Pahat Terhadap Struktur Mikro dan Kekerasan Mikro Pada Hasil Pengelasan FSW Logam Tak Sejenis Aluminium dan Tembaga," Prosiding SNTTM 16, Surabaya

[9] Mehta, K.P., dan Badheka, V.J., 2016, "Effects of tool tilt angle on properties of dissimilar friction stir welding copper to aluminum," Materials and Manufacturing Processes 31(3): 233-254.

[10] Savolainen, K. 2012, "Friction stir welding of copper and microstructure and properties of the welds," Helsinki, Aalto University (PhD thesis), Finland.

[11] Mehta, K., dan Badheka, V., 2014, "Investigations on friction stir welding defects for dissimilar copper to aluminum materials under different process parameters," In Proceedings of International Conference on Friction based Processes (ICFP-2014), IISc, Bangalore, India.

[12] Esmaeili, A., Besharati Givi, M.K., Zareie Rajani, H.R., 2012, "Experimental investigation of material flow and welding defects in friction stir welding of aluminum to brass," Materials and Manufacturing Processes, vol: 27 (12): 1402-1408.

[13] Mubiayi, M.P. dan Akinlabi, E.T., 2013, "Friction stir welding of materials between aluminum alloys and copperAn overview," In Proceedings of the World Congress on Engineering, London, UK, July 2013: 978-988.

[14] Tan, C.W., Jiang, Z.G., Li, L.Q., Chen, Y.B., Chen, X.Y., 2013, "Microstructural evolution and mechanical properties of dissimilar Al-Cu joints produced by friction stir welding," Materials and Design: 466-473.

[15] Dwivedi, D. K., 2010, “Adhesive wear behaviour of cast aluminium-silicon alloys: overview," Materials \& Design, 31(5): 2517-2531

[16] Liu, H.J., Shen, J.J., Zhou, L., Zhao, Y.Q., Liu, C., Kuang, L.Y., 2011, "Microstructural characterisation and mechanical properties of friction stir welded joints of aluminium alloy to copper," Science and Technology of Welding \& Joining, 16: 92-98. 